NASA/TM-2003-212498

\title{
Predicting the Reliability of Ceramics Under Transient Loads and Temperatures With CARES/Life
}

Noel N. Nemeth

Glenn Research Center, Cleveland, Ohio

Osama M. Jadaan

University of Wisconsin, Platteville, Platteville, Wisconsin

Tamas Palfi

Budapest University of Technology and Economics, Budapest, Hungary

Eric H. Baker

Connecticut Reserve Technologies, Stow, Ohio 
Since its founding, NASA has been dedicated to the advancement of aeronautics and space science. The NASA Scientific and Technical Information (STI) Program Office plays a key part in helping NASA maintain this important role.

The NASA STI Program Office is operated by Langley Research Center, the Lead Center for NASA's scientific and technical information. The NASA STI Program Office provides access to the NASA STI Database, the largest collection of aeronautical and space science STI in the world. The Program Office is also NASA's institutional mechanism for disseminating the results of its research and development activities. These results are published by NASA in the NASA STI Report Series, which includes the following report types:

- $\quad$ TECHNICAL PUBLICATION. Reports of completed research or a major significant phase of research that present the results of NASA programs and include extensive data or theoretical analysis. Includes compilations of significant scientific and technical data and information deemed to be of continuing reference value. NASA's counterpart of peerreviewed formal professional papers but has less stringent limitations on manuscript length and extent of graphic presentations.

- TECHNICAL MEMORANDUM. Scientific and technical findings that are preliminary or of specialized interest, e.g., quick release reports, working papers, and bibliographies that contain minimal annotation. Does not contain extensive analysis.

- CONTRACTOR REPORT. Scientific and technical findings by NASA-sponsored contractors and grantees.
- CONFERENCE PUBLICATION. Collected papers from scientific and technical conferences, symposia, seminars, or other meetings sponsored or cosponsored by NASA.

- SPECIAL PUBLICATION. Scientific, technical, or historical information from NASA programs, projects, and missions, often concerned with subjects having substantial public interest.

- TECHNICAL TRANSLATION. Englishlanguage translations of foreign scientific and technical material pertinent to NASA's mission.

Specialized services that complement the STI Program Office's diverse offerings include creating custom thesauri, building customized databases, organizing and publishing research results ... even providing videos.

For more information about the NASA STI Program Office, see the following:

- Access the NASA STI Program Home Page at http://www.sti.nasa.gov

- E-mail your question via the Internet to help@sti.nasa.gov

- Fax your question to the NASA Access Help Desk at 301-621-0134

- Telephone the NASA Access Help Desk at 301-621-0390

- Write to:

NASA Access Help Desk

NASA Center for AeroSpace Information 7121 Standard Drive

Hanover, MD 21076 
NASA/TM-2003-212498

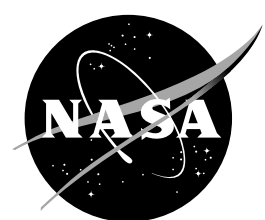

\section{Predicting the Reliability of Ceramics Under Transient Loads and Temperatures With CARES/Life}

Noel N. Nemeth

Glenn Research Center, Cleveland, Ohio

Osama M. Jadaan

University of Wisconsin, Platteville, Platteville, Wisconsin

Tamas Palfi

Budapest University of Technology and Economics, Budapest, Hungary

Eric H. Baker

Connecticut Reserve Technologies, Stow, Ohio

Prepared for the

Symposium on Probabilistic Aspects of Life Prediction

sponsored by the American Society for Testing and Materials

Miami, Florida, November 6-7, 2002

National Aeronautics and

Space Administration

Glenn Research Center 


\section{Acknowledgments}

We would like to thank Dr. Uwe Rettig and Dr. Matt Ferber for providing data from the IEA study on thermally shocked disks, and Dr. John Gyekenyesi for his support and technical direction over the years. We also thank

Debbie Haught, DOE Office of Industrial Technologies, and Carol Ginty, Manager, NASA Hot Propulsion Components Program.

Trade names or manufacturers' names are used in this report for identification only. This usage does not constitute an official endorsement, either expressed or implied, by the National Aeronautics and Space Administration.

The Propulsion and Power Program at NASA Glenn Research Center sponsored this work.

Available from

NASA Center for Aerospace Information 7121 Standard Drive

Hanover, MD 21076
National Technical Information Service 5285 Port Royal Road Springfield, VA 22100 


\title{
Predicting the Reliability of Ceramics Under Transient Loads and Temperatures with CARES/Life
}

\author{
Noel N. Nemeth ${ }^{1}$ \\ National Aeronautics and Space Administration \\ Glenn Research Center \\ Cleveland, Ohio \\ Osama M. Jadaan ${ }^{2}$ \\ University of Wisconsin, Platteville \\ Platteville, Wisconsin \\ Tamas Palfi ${ }^{3}$ \\ Budapest University of Technology and Economics \\ Budapest, Hungary \\ Eric H. Baker ${ }^{4}$ \\ Connecticut Reserve Technologies \\ Stow, Ohio
}

\begin{abstract}
A methodology is shown for predicting the time-dependent reliability of ceramic components against catastrophic rupture when subjected to transient thermomechanical loads (including cyclic loads). The methodology takes into account the changes in material response that can occur with temperature or time (i.e., changing fatigue and Weibull parameters with temperature or time). This capability has been added to the NASA CARES/Life (Ceramic Analysis and Reliability Evaluation of Structures/Life) code. The code has been modified to have the ability to interface with commercially available finite element analysis (FEA) codes executed for transient load histories. Examples are provided to demonstrate the features of the methodology as implemented in the CARES/Life program.
\end{abstract}

\section{Nomenclature}

A slow crack growth coefficient $\left(\mathrm{A}_{1}-\right.$ power law, $\mathrm{A}_{2}-$ Walker law $)$

$\mathrm{A}_{\mathrm{e}} \quad$ effective area

a crack length

B slow crack growth material parameter

$\overline{\mathrm{C}} \quad$ Shetty shear sensitivity constant

CARES Ceramics Analysis and Reliability Evaluation of Structures

$f_{c} \quad$ cyclic frequency

FEA Finite Element Analysis

$\mathrm{K}_{\mathrm{i}} \quad$ Stress intensity factor ( $\mathrm{i}=\mathrm{I}$, II, III for modes I, II, or III, respectively)

\footnotetext{
${ }^{1}$ Research Engineer, Life Prediction Branch

${ }^{2}$ Professor, College of Engineering, Mathematics, and Science, University of Wisconsin-Platteville

${ }^{3} \mathrm{Ph} . \mathrm{D}$. Student, Budapest University of Technology and Economics

${ }^{4}$ Research Engineer
} 


\begin{tabular}{|c|c|}
\hline $\mathrm{K}_{\mathrm{Ic}}$ & critical mode I stress intensity factor (fracture toughness) \\
\hline $\mathrm{K}_{\text {Ieq }}$ & equivalent mode I stress intensity factor from applied effective stress \\
\hline $\mathrm{K}_{\text {Ieq, cyclic }_{\max }}$ & maximum mode I equivalent stress-intensity factor over a cycle \\
\hline$\overline{\mathrm{k}}_{\mathrm{B}}$ & normalized Batdorf crack density coefficient \\
\hline $\mathrm{m}$ & Weibull modulus (scatter parameter) \\
\hline $\mathrm{N}$ & slow crack growth exponent \\
\hline $\mathrm{P}_{\mathrm{fa}}$ & attenuated probability of failure from proof test and service load \\
\hline $\mathrm{P}_{\mathrm{f}}$ & probability of failure $\left(\mathrm{P}_{\mathrm{f}}=1-\mathrm{P}_{\mathrm{s}}\right)$ \\
\hline $\mathrm{P}_{\mathrm{S}}\left(\mathrm{t}_{\mathrm{f}}\right)$ & probability of survival at time $\mathrm{t}=\mathrm{t}_{\mathrm{f}}$ \\
\hline $\mathrm{P}_{\mathrm{Sa}}$ & attenuated probability of survival from proof test and service load \\
\hline $\mathrm{P}_{\mathrm{Si}}$ & probability of survival from proof test and service load \\
\hline $\mathrm{P}_{\mathrm{Sp}}$ & probability of survival from proof test \\
\hline Q & Walker law R-ratio sensitivity exponent \\
\hline $\mathrm{R}$ & R-ratio; ratio of minimum stress divided by maximum cyclic stress \\
\hline S & surface area based property (indicates surface flaw analysis) \\
\hline SCG & Slow Crack Growth \\
\hline $\mathrm{T}$ & temperature \\
\hline $\mathrm{t}$ & time \\
\hline$t_{\mathrm{p}}$ & proof test time \\
\hline $\mathrm{t}_{\mathrm{q}}$ & total time in proof testing and service \\
\hline $\mathrm{V}$ & volume, or volume based property (indicates volume flaw analysis) \\
\hline $\mathrm{V}_{\mathrm{e}}$ & effective volume \\
\hline Y & crack geometry correction factor \\
\hline $\mathrm{x}, \mathrm{y}, \mathrm{z}$ & represents a location in the body of the structure \\
\hline Z & number of load blocks or number of cycles \\
\hline$\Delta$ & increment or difference \\
\hline$\Delta \mathrm{t}_{\mathrm{j}}$ & duration of time step $\mathrm{j}$ \\
\hline$\sigma_{\mathrm{f}}$ & represents the peak stress in a component \\
\hline$\sigma_{\text {Ieq }}$ & equivalent mode I far-field stress \\
\hline$\sigma_{\text {Ieq,j }}$ & equivalent mode I far-field stress during time step $\mathrm{j}$ \\
\hline$\sigma_{\text {Ieq, }, \text { Tmax }}$ & maximum transformed stress during k time steps \\
\hline$\sigma_{\mathrm{n}}$ & applied far-field stress normal to a crack face \\
\hline$\sigma_{0}$ & Weibull scale parameter \\
\hline$\sigma_{0 \mathrm{~B}}$ & Weibull scale parameter incorporating the effect of $\overline{\mathrm{k}}_{\mathrm{B}}$ \\
\hline$\sigma_{\theta}$ & characteristic strength (value of $\sigma_{f}$ where $63.21 \%$ of specimens fail) \\
\hline$\tau$ & applied far-field shear stress on a crack face \\
\hline$\Psi$ & represents a location $(x, y, z)$ and crack orientation $(\alpha, \beta)$ \\
\hline $\mathrm{d} \Omega$ & $\sin \alpha \mathrm{d} \alpha \mathrm{d} \beta$ \\
\hline
\end{tabular}

\section{Introduction}

Ceramic materials display a stochastic strength response because of the combination of brittleness and the random nature of the size, orientation, and distribution of inherent microscopic flaws. In addition, the ability of ceramic structures to sustain loads degrades over time due to a variety of effects such as slow crack growth (SCG), cyclic fatigue, 
creep, and oxidation. Life prediction codes such as CARES/Life [1], CERAMIC/ERICA [2], and STAU [3] are available and have been demonstrated to be successful in predicting the probability of ceramic components failing from spontaneous catastrophic rupture when these components are subjected to multiaxial loading and SCG conditions. The objective of this paper is to describe and demonstrate the methodology employed in the CARES/Life code that enables the calculation of component failure probability when loading and temperature varies over time. This capability is referred to as transient reliability analysis and can be used to predict component reliability for situations such as thermal shock, startup and shutdown conditions in heat engines, and cyclic loading. This computational methodology is an extension to the work of Paluszny and Nichols [4], Stanley and Chau [5] and Ziegler [6].

For the CARES/Life program the transient reliability analysis methodology is developed with the following features:

a) Fast-fracture transient analysis (reliability analysis without SCG).

b) SCG transient modeling with SCG and Weibull parameters (including the shape parameter, $\mathrm{m}$ ) allowed to vary with time and temperature.

c) Computationally efficient algorithm to compute reliability for cyclic loading.

d) Cyclic fatigue modeling using a combined SCG and Walker fatigue law.

e) Transient proof test capability.

Three example problems are shown; 1) A disk in thermal shock to illustrate fastfracture transient analysis, 2) a diesel engine exhaust valve to contrast predictions for cyclic loading and proof testing, and 3) the effect of changing Weibull and fatigue parameters over time on the reliability of alumina flexure bars in static fatigue.

\section{Methodology}

The detailed development of the transient reliability methodology for SCG for the CARES/Life program has been described in $[7,8]$ and will not be repeated here. Instead a highlight of these equations will be presented as well as a proposed relation for cyclic fatigue.

The CARES/Life software describes the probabilistic nature of material strength using the Weibull cumulative distribution function [9]. For uniaxially stressed components the 2parameter Weibull distribution for volume residing flaws describes the component fastfracture failure probability, $\mathrm{P}_{\mathrm{fv}}$, as

$$
\mathrm{P}_{\mathrm{fV}}=1-\exp \left[-\frac{1}{\sigma_{0 \mathrm{~V}} \mathrm{~m}_{\mathrm{V}}} \int_{\mathrm{V}} \sigma(\mathrm{x}, \mathrm{y}, \mathrm{z})^{\mathrm{m}_{\mathrm{V}}} \mathrm{dV}\right]
$$

where $\mathrm{V}$ is the volume, terms that are a function of volume have $\mathrm{V}$ in the subscript, $\sigma(\mathrm{x}, \mathrm{y}, \mathrm{z})$ is the uniaxial stress at a point location in the body, and $\mathrm{m}$ and $\sigma_{0}$ are the shape and scale parameters of the Weibull distribution, respectively. The shape parameter is a (unitless) measure of the dispersion of strength while the scale parameter is the characteristic strength of a unit volume of material in uniaxial tension and has units of stress.volume ${ }^{1 / \mathrm{m}}$. An analogous equation based on surface area can be shown for flaws that exclusively reside on 
the component surface. However, for the sake of brevity this paper is restricted to showing volume flaw based relations only.

Determination of the Weibull parameters comes from rupture experiments of specimens in simple tension or flexure. Regression techniques such as least squares and maximum likelihood have been developed that can determine these parameters from a simplified form of equation (1);

$$
\begin{aligned}
& P_{f V}=1-\exp \left[-\int_{V}\left(\frac{\sigma(x, y, z)}{\sigma_{f}}\right)^{m_{V}} d V\left(\frac{\sigma_{f}}{\sigma_{0 V}}\right)^{m_{V}}\right] \\
& =1-\exp \left[-\left(\frac{\sigma_{f}}{\sigma_{\theta V}}\right)^{m_{V}}\right]=1-\exp \left[-V_{e}\left(\frac{\sigma_{f}}{\sigma_{0 V}}\right)^{m_{V}}\right]
\end{aligned}
$$

where $\sigma_{\mathrm{f}}$ is the peak stress in the specimen, $\sigma_{\theta \mathrm{V}}$ is the specimen characteristic strength, and $\mathrm{V}_{\mathrm{e}}$ is known as the effective volume.

To predict component reliability for multiaxial stress states the Batdorf theory $[10,11]$ is used. Batdorf theory combines the weakest link theory with linear elastic fracture mechanics. It includes the calculation of the combined probability of the critical flaw being within a certain size range and being located and oriented so that it may cause fracture.

Slow crack growth refers to the stable extension of a crack over time. It results from the combination of stress at the crack tip and chemical attack such that chemical bonds break and the crack tip extends. At high temperatures it can also occur from the action of stress and the loosening of viscous phases such that material at the crack tip displaces. The crack length, a, as a function of time, $t$, can be expressed as a power law [12] with the following form

$$
\frac{\mathrm{da}(\Psi, \mathrm{t})}{\mathrm{dt}}=\mathrm{A}(\mathrm{x}, \mathrm{y}, \mathrm{z}, \mathrm{t}) \mathrm{K}_{\mathrm{leq}}^{\mathrm{N}(\mathrm{x}, \mathrm{y}, \mathrm{z}, \mathrm{t})}(\Psi, \mathrm{t})
$$

where $\mathrm{K}_{\text {Ieq }}$ is the equivalent mode I stress intensity factor from the applied effective stress, $(\Psi, \mathrm{t})$ denotes a term that is a function of $\Psi$ (indicating a location $(\mathrm{x}, \mathrm{y}, \mathrm{z})$ and crack orientation described by angles $\alpha$, and $\beta$ ) and $t$, and $A$ and $N$ are material parameters that depend on the temperature and environment and hence become a function of time and location but not orientation.

To take into account the time dependence of loading and material response, we discretize the stress history for each finite element $\mathrm{i}$ into short time steps $\left(\Delta \mathrm{t}_{\mathrm{j}}\right)$ during which the stress and material parameters are assumed to remain constant over that time step interval. For a specific time step $\mathrm{j}$, the applied equivalent stress in element $\mathrm{i}$ is given by $\sigma_{\text {Ieq }, j}$, the temperature $T_{j}$, the scale parameter $\sigma_{0 \mathrm{Vj}}$, the Weibull modulus $\mathrm{m}_{\mathrm{Vj}}$, the fatigue constant $\mathrm{B}_{\mathrm{Vj}}$, and the fatigue exponent $\mathrm{N}_{\mathrm{Vj}}$. At time $\mathrm{t}_{\mathrm{k}}$ (for $\mathrm{k}$ time steps) the component survival probability, using the Batdorf approach, can be expressed as 


$$
\begin{aligned}
& \mathrm{P}_{\mathrm{SV}}\left(\mathrm{t}_{\mathrm{k}}\right)=\exp \left\{-\sum_{\mathrm{i}=1}^{\mathrm{n}} \frac{\mathrm{V}_{\mathrm{i}}}{4 \pi}\left[\int _ { \Omega } \left[\ldots \left[\left[\left(\frac{\sigma_{\text {Ieq, }, \mathrm{T} \text { max }}}{\sigma_{0 \mathrm{BVk}}}\right)^{\mathrm{N}_{\mathrm{Vk}}-2}+\right.\right.\right.\right.\right.
\end{aligned}
$$

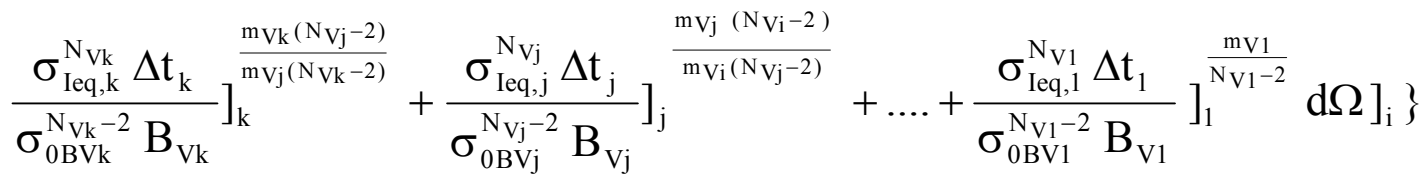

where, for example

$$
\begin{gathered}
\sigma_{0 \mathrm{BVj}}=\left(\frac{\sigma_{0 \mathrm{Vj}}}{\left[\overline{\mathrm{k}}_{\mathrm{BVj}}\right]^{1 / \mathrm{m}_{\mathrm{Vj}}}}\right) \\
\mathrm{B}_{\mathrm{Vj}}=\frac{2}{\mathrm{~A}_{\mathrm{j}} \mathrm{Y}^{2} \mathrm{~K}_{\mathrm{IC}, \mathrm{j}}{ }^{\mathrm{N}_{\mathrm{Vj}}-2}\left(\mathrm{~N}_{\mathrm{Vj}}-2\right)}
\end{gathered}
$$

The fatigue parameter $\mathrm{B}$ has units stress ${ }^{2} \times$ time. $\mathrm{Y}$ is the crack geometry correction factor, $\mathrm{K}_{\mathrm{IC}}$ is the critical mode I stress intensity factor, $\sigma_{\text {Ieq,k,Tmax }}$ represents the effective stress examined over $\mathrm{k}$ time steps which yields the highest fast-fracture failure probability [5-8], and $\mathrm{d} \Omega=\sin \alpha \mathrm{d} \alpha \mathrm{d} \beta$. Most of the terms in these equations are functions of $\Psi$ and t. Equation (4) was developed based on an approach of using flaw strength and maintaining compatibility of failure probability between discrete time steps. This methodology allows for the introduction of a variable Weibull modulus as a function of time or temperature. The effective stress $\sigma_{\text {Ieq,j }}$ represents an equivalent normal stress on the crack face caused by the combined action of the normal stress $\sigma_{\mathrm{n}, \mathrm{j}}$ and the shear stress $\tau_{\mathrm{j}}$ on the crack face, oriented normal to angles $\alpha$ and $\beta$ - which define the orientation of the flaw. A mixed-mode fracture criterion and an assumed crack shape define the relationship for the equivalent stress. A parameter, $\bar{C}$, known as the Shetty shearsensitivity coefficient [13], is used in CARES/Life to weight the contribution of $\tau_{\mathrm{j}}$ relative to $\sigma_{\mathrm{n}, \mathrm{j}}$ for the equivalent stress. Shetty [13] has found this parameter to range between $0.80 \leq \overline{\mathrm{C}} \leq 2.0$. As $\overline{\mathrm{C}}$ increases, the response becomes progressively more shear insensitive. The term $\overline{\mathrm{k}}_{\mathrm{BVj}}$ in equation (5) is the normalized Batdorf crack density coefficient for volume flaws. It is used in the reliability equation for compatibility purposes. It insures that the multiaxial Batdorf theory collapses to the basic uniaxial Weibull equation (1) when a uniaxial stress state is applied for a single time step solution. Also, it needs to be clarified that for increased numerical accuracy CARES/Life further subdivides each of the elements into their constituent Gaussian integration points and performs calculations in equations $(4,5,6)$ based on these values.

Repeated Block (Cyclic) Loading-Repeated block loading refers to a single cycle or a group of cycles (a block) that are applied repeatedly. Using equation (4) if $\mathrm{k}$ number of time steps describes the first load block, then for $Z$ number of load blocks equation (4) requires $\mathrm{k} \cdot \mathrm{Z}$ number of time steps in order to calculate a reliability solution. Obviously, 
this quickly becomes computationally intensive when reliability solutions for large block (or cycle) counts are desired. As an alternative the authors have developed a more computationally efficient means to perform this task [8]. This approximation method allows for a tradeoff between solution accuracy and numerical efficiency. In its most computationally efficient form this equation is expressed as

$$
\begin{aligned}
P_{S V}\left(Z t_{k}\right)= & \exp \left\{-\sum_{\mathrm{i}=1}^{\mathrm{n}} \frac{\mathrm{V}_{\mathrm{i}}}{4 \pi}\left[\int _ { \Omega } \left[\ldots \left[\left[\left(\frac{\sigma_{\text {Ieq, }, T_{\text {Max }}}}{\sigma_{0 B V k}}\right)^{N_{v k}-2}+\right.\right.\right.\right.\right. \\
& \left.\left.\left.\left.\left.\frac{\sigma_{\text {Ieq, }}^{N_{v k}} Z \Delta t_{k}}{\sigma_{0 B V k}^{N_{v k}-2} B_{v k}}\right]_{k}^{\frac{m_{v k}\left(N_{v j}-2\right)}{m_{v j}\left(N_{v k}-2\right)}}+\frac{\sigma_{I e q, j}^{N_{v j}} Z \Delta t_{j}}{\sigma_{0 B V j}^{N_{v j}-2} B_{v j}}\right]_{j}^{\frac{m_{i j}\left(N_{v i-2}\right)}{m_{v i}\left(N_{v j-2)}\right.}}+\ldots+\frac{\sigma_{I e q, 1}^{N_{v 1}} Z \Delta t_{1}}{\sigma_{0 B V 1}^{N_{v 1}-2} B_{v 1}}\right]_{1}^{\frac{m_{v 1}}{N_{v 1}-2}} d \Omega\right]_{i}\right\}
\end{aligned}
$$

where it can be seen that only $\mathrm{k}$ computation steps are required to solve the equation regardless of the number of load blocks $\mathrm{Z}$.

Combined Fatigue and SCG Behavior-Equation (7) for component reliability is based on the power law shown in equation (3). This equation is affected by the shape of the cyclic wave form and is predicted to be less damaging than static loading - when the static load is the peak stress of the wave form applied over the same service time as the cyclic load. Glasses seem to follow this behavior well, while polycrystalline materials may show more complex behavior under cyclic loading. Damage from cyclic loading can be caused by a variety of effects, such as debris wedging or the degradation of bridging ligaments, but essentially it is based on the accumulation of some type of irreversible damage that tends to enhance the crack growth. To empirically account for cyclic effects the CARES/LIFE program has implemented the Walker law [14], which traditionally has been used for metal fatigue, superimposed with the power law [15]

$$
\begin{aligned}
\frac{\mathrm{da}(\Psi, \mathrm{t})}{\mathrm{dt}}= & \mathrm{A}_{1 \mathrm{~V}}(\mathrm{x}, \mathrm{y}, \mathrm{z}, \mathrm{t}) \mathrm{K}_{\text {Ieq }}(\Psi, \mathrm{t})^{\mathrm{N}_{\mathrm{V}}(\mathrm{x}, \mathrm{y}, \mathrm{z}, \mathrm{t})}+ \\
& \mathrm{f}_{\mathrm{c}} \mathrm{A}_{2 \mathrm{~V}}(\mathrm{x}, \mathrm{y}, \mathrm{z}, \mathrm{t}) \mathrm{K}_{\text {Ieq, cyclic } \max }(\Psi, \mathrm{t})^{\mathrm{N}_{\mathrm{V}}(\mathrm{x}, \mathrm{y}, \mathrm{z}, \mathrm{t})-\mathrm{Q}_{\mathrm{V}}(\mathrm{x}, \mathrm{y}, \mathrm{z}, \mathrm{t})} \Delta \mathrm{K}_{\text {Ieq }}(\Psi, \mathrm{t})^{\mathrm{Q}_{\mathrm{V}}(\mathrm{x}, \mathrm{y}, \mathrm{z}, \mathrm{t})}
\end{aligned}
$$

where $A_{1}, A_{2}, N$, and $Q$ are material constants which depend on temperature, $K_{\text {Ieq }}(\Psi, t)$ is mode I equivalent stress-intensity factor at location/orientation $\Psi, \mathrm{K}_{\text {Ieq, cyclic } \max }(\Psi, \mathrm{t})$ is the maximum mode I equivalent stress-intensity factor (i.e., the maximum value of $\mathrm{K}_{\text {Ieq }}$ over the cycle at location/orientation $\Psi), \Delta \mathrm{K}_{\text {Ieq }}(\Psi, \mathrm{t})$ is the range of mode I equivalent stressintensity factor at $\Psi$, and $\mathrm{f}_{\mathrm{c}}$ is the frequency. A methodology for estimating these parameters from cyclic fatigue specimen rupture data is described in [15]. The values of $\mathrm{A}_{1}, \mathrm{~A}_{2}, \mathrm{~N}$, and $\mathrm{Q}$ in equation (8) depend on location $\mathrm{x}, \mathrm{y}, \mathrm{z}$ and time t. We will assume that $\mathrm{da}(\Psi, \mathrm{t}) / \mathrm{dt}$ is continuous at fractions of a cycle, that is, we assume $\mathrm{da}(\Psi, \mathrm{t}) / \mathrm{dt}$ could be computed for non-integer (real number) cycle counts. The advantage equation (8) has over the Walker law for ceramic materials is that when the range of the stress intensity factor $\Delta \mathrm{K}_{\text {Ieq }}$ is zero, crack growth is not predicted to be zero in the presence of a static 
load. Following the same derivation methodologies in $[7,8]$ an equation similar to equation (7) can be constructed

$$
\begin{aligned}
& P_{S V}\left(Z t_{k}\right)=\exp \left\{-\sum_{\mathrm{i}=1}^{\mathrm{n}} \frac{\mathrm{V}_{\mathrm{i}}}{4 \pi}\left[\int_{\Omega}[\ldots[\right.\right. \\
& {\left[\left(\frac{\sigma_{\text {Ieq }, k, T_{M a x}}}{\sigma_{0 B V k}}\right)^{N_{V k}-2}+\frac{\left.\sigma_{I e q, k}^{N_{V k}}\left(1+\left(\frac{\sigma_{\text {Ieq }, k, T_{M a x}}}{\sigma_{\text {Ieq }, k}}\right)^{N_{V k}} f_{c}\left(\frac{A_{2}}{A_{1}}\right)_{V k}(1-R)^{Q_{V k}}\right\} Z \Delta t_{k}\right]_{k}^{\sigma_{0 B V k}^{N_{V k}-2} B_{V k}}}{m_{V_{V V}\left(N_{V j}-2\right)}^{\left.m_{V k}-2\right)}}\right.}
\end{aligned}
$$

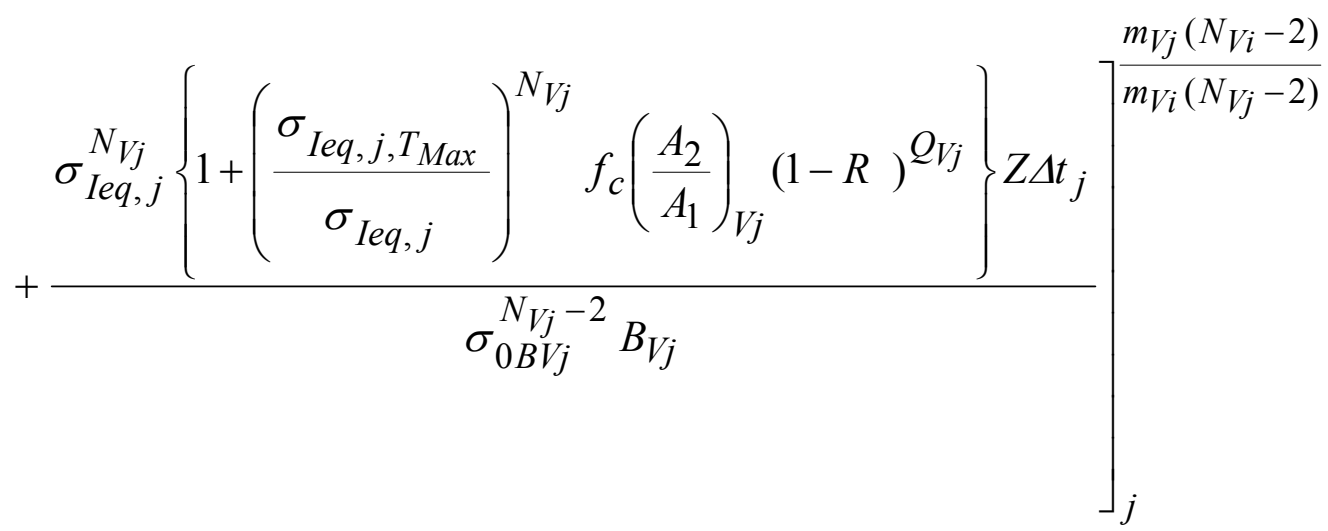

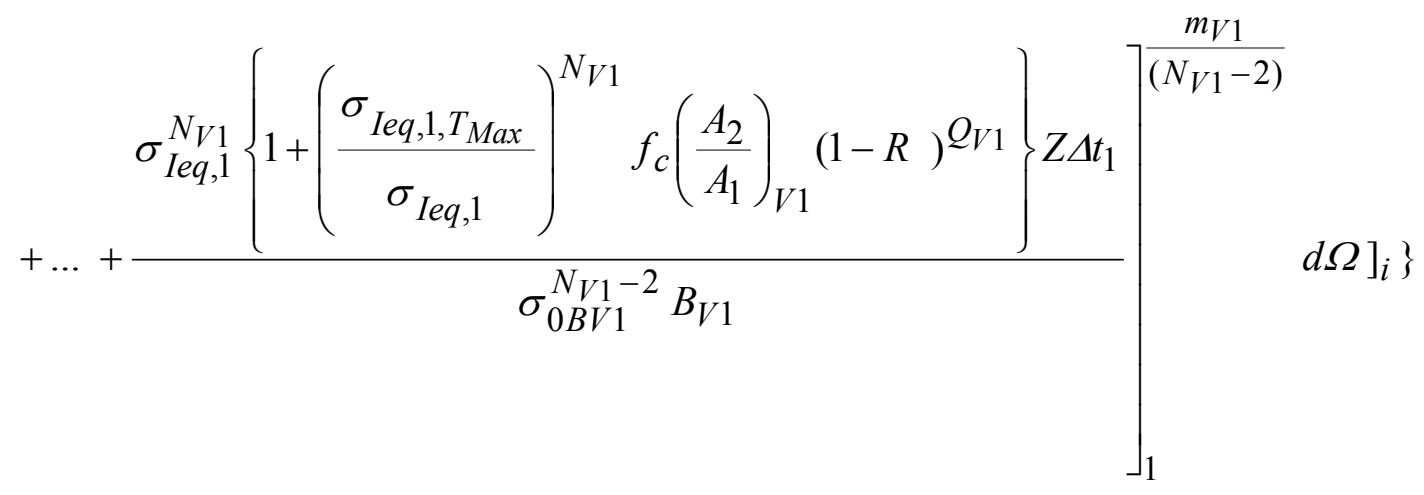

where $\mathrm{R}$ is the R-ratio, shown below as a function of $\Psi$ and $\mathrm{t}$ 


$$
\mathrm{R}(\Psi, \mathrm{t})=\frac{\sigma_{\text {Ieq, cyclic }_{\min }}(\Psi, \mathrm{t})}{\sigma_{\text {Ieq, }, \text { yclic }_{\max }}(\Psi, \mathrm{t})}
$$

There are limitations associated with equation (9) and it's implementation in CARES/Life. The first is that the equation represents an averaging of properties over the cycle. There is no weighting given to whether the time step is at the peak or trough of the cycle - all time steps are weighted equally regarding their damage contribution. Thus, equation (9) is not a true thermomechanical fatigue methodology for brittle material transient reliability analysis. It is however usable when parameters are constant or vary little over the cycle. In CARES/Life $\mathrm{R}(\Psi, \mathrm{t})$ is calculated by examining all time steps; therefore the transient FEA must be restricted to one cycle of loading when equation (9) is used.

Proof Testing-Prior to placing a ceramic component in service, confidence that it will perform reliably is usually demonstrated through proof testing. Ideally, the boundary conditions applied to a component under proof testing simulate the conditions that the component would be subjected to in service. Additionally the proof test loads are designed to be appropriately greater in magnitude over a fixed time interval $t_{p}$. After proof testing, the survived component is placed in service with greater confidence in its integrity and a predictable minimum service life, $t_{\min }$, where no failure should theoretically occur.

The attenuated probability of failure, $\mathrm{P}_{\mathrm{faV}}$, of a component surviving proof testing for time $t_{p}$ and subjected to an arbitrary (but known) service history over a time interval $\left(t_{q}\right.$ $\left.t_{p}\right)$ is

$$
\mathrm{P}_{\mathrm{faV}}\left(\mathrm{t}_{\mathrm{q}}\right)=1-\mathrm{P}_{S \mathrm{aV}}\left(\mathrm{t}_{\mathrm{q}}\right)=1-\frac{\mathrm{P}_{S \mathrm{iV}}\left(\mathrm{t}_{\mathrm{q}}\right)}{\mathrm{P}_{S \mathrm{pV}}\left(\mathrm{t}_{\mathrm{p}}\right)}
$$

The term $\mathrm{P}_{\mathrm{SpV}}\left(\mathrm{t}_{\mathrm{p}}\right)$ is the probability of survival of a component subjected to a proof test over a time interval denoted by $t_{p}$. The term $P_{\mathrm{Siv}}\left(\mathrm{t}_{\mathrm{q}}\right)$ is the probability of survival of a component subjected to a proof test equivalent stress distribution $\sigma_{\text {Ieqp }}(\Psi, t)$ over time interval $t_{p}$ and an in service equivalent stress distribution $\sigma_{\text {Ieq }}(\Psi, t)$ over time interval $\left(t_{q}\right.$ $t_{p}$ ). The reliability of the survived component increases as the ratio of the proof test stress to the service stress increases.

In the CARES/Life program the computation associated with equation (11) is not performed at the component level, but rather at $\Psi$, a given $\mathrm{x}, \mathrm{y}, \mathrm{z}$ location and flaw orientation $\alpha, \beta$. Therefore the proof test loading does not have to exactly simulate the service loading. For example, the proof test load and the service load can be applied in different directions. Further details of this methodology are described in [1] and the extension to transient reliability analysis is reasonably straightforward.

\section{Examples}

\section{Example 1: Thermal Shocked Disk In Fast-Fracture}

In this example we examine the fast-fracture reliability response of a laser induced thermal shocked disk made of silicon nitride. The purpose is to see if we can predict the 
strength response of the disks from rupture data of simple beams in uniaxial flexure. We will also compare the transient fast-facture reliability predictions of the disk versus the instantaneous fast-fracture reliability predictions of a given time step in order to verify the correctness and accuracy of the numerical algorithm. This example is derived from an international study involving laboratories from Germany, Japan, and the United States [16]. Phase I of that study worked to develop and verify thermal up-shock techniques in which a disk specimen was centrally heated to fracture by an appropriate heating source, including laser, quartz lamp, shaped heating element, and gas torch. Phase II of the study involved a round-robin between the three countries testing thermal fracture stress for two silicon nitrides, AlliedSignal's AS800 and Kyocera's SN282. For this example we used disk results from the Siemens AG organization, as provided by Rettig [17], for the SN282 material. These disks were tested using the laser irradiation technique described by Kirchhoff [18] and Rettig [19]. We also used three-point flexure bar data that was provided by Ferber [20].

Thin disks $20 \mathrm{~mm}$ in diameter and $0.3 \mathrm{~mm}$ thick were centrally heated by a $800 \mathrm{~W}$ laser working in continuous wave mode. A large centrally heated area and a steep temperature gradient near the edge was created, which yielded high tensile stresses near the edge. The specimens were rapidly heated so that fracture would occur in less than a second. The temperature versus time response across the disk was measured with a fast scanning pyrometer. The heating time and the thinness of the disk were chosen such that through-thickness temperature gradients (and hence bending stresses) were negligible. Further details regarding the experimental set-up are found in $[16,18,19]$.

A total of 15 disks were fractured. The time of rupture and the radius corresponding to the location of fracture was recorded for each specimen. Fracture stresses were computed by the study participants using the temperature profile at the instant of fracture, temperature dependent elastic modulus and thermal expansion coefficient, and integral equations from standard elasticity theory. Some of the disks were cut into three-point flexure specimens in order to independently quantify the strength characteristics. Fourteen of these flexure specimens were tested at room temperature with average size of $0.30 \mathrm{~mm}$ thick, $3.25 \mathrm{~mm}$ width, $15.00 \mathrm{~mm}$ long with a support span of $9.44 \mathrm{~mm}$. The specimen edges were not beveled.

In order to perform the CARES/Life reliability analysis an ANSYS finite element model of the disk was prepared. The model comprised a $90^{\circ}$ slice of the disk and spanned $1 / 2$ the thickness ( $1 / 8$ of the disk is modeled). Solid elements were used in the model. The disk was not constrained (other than to prevent rigid body motion) and thus was freely allowed to expand. Temperature dependent thermal expansion and elastic modulus values from [16] were used. The thermal loading profiles versus time for two specimens (designated as \#3 and \#9) as supplied by Rettig [17] were used for the thermal loading. The temperatures were assumed constant through the thickness. Specimen \#3 had the highest time to failure of 0.65 seconds and, hence, the highest reported fracture strength of $430 \mathrm{MPa}$ [16]. Specimen \#9 had an intermediate fracture strength of $340 \mathrm{MPa}$ [16]. Figure 1 (a) shows the transient thermal profile for specimen \#3. Figure 1 (b) shows the specimen \#3 transient stress analysis results from the FEA.

The figure shows the tangential (circumferential) stresses versus distance from the disk center. The tangential stresses are compressive near the disk center and become tensile towards the disk edge. The radial stresses are always compressive and are not 

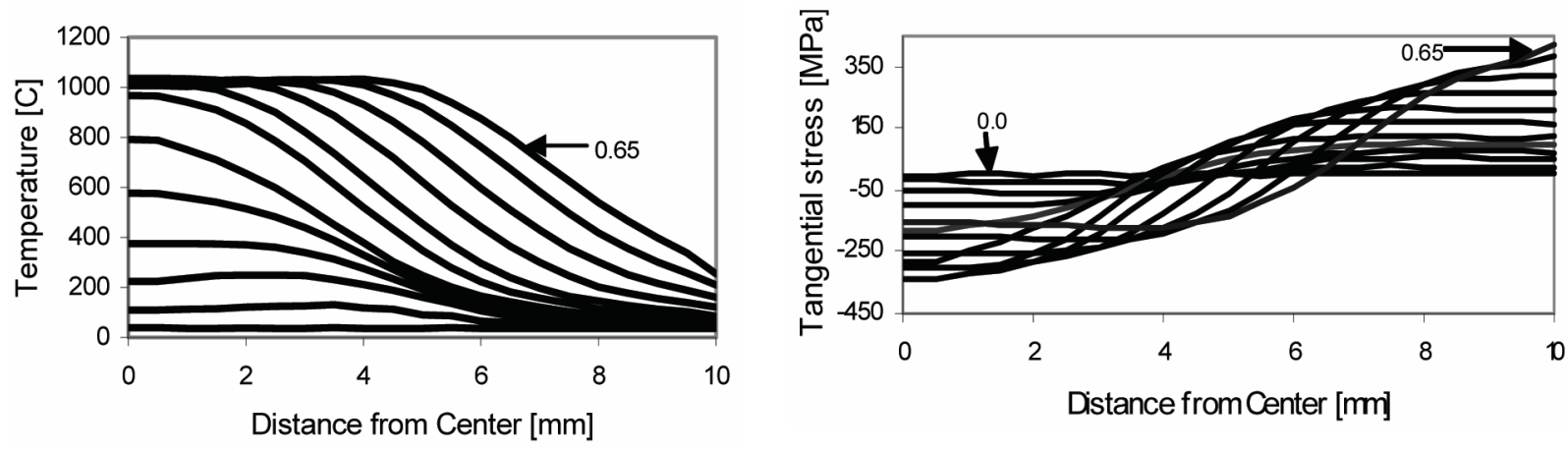

FIG. 1-Disk specimen \#3 - (a) Transient thermal profile, and (b) Transient tangential stress profile. Time steps range from 0.0 to 0.65 seconds. Not all time steps are shown.

shown. The FEA analysis for specimen \#3 consisted of 27 time steps ranging from 0.0 to 0.65 seconds, while the analysis for specimen \#9 consisted of 15 time steps ranging from 0.0 to 0.35 seconds. The FEA transient tangential stress results compared very well with the numerical calculations performed by the Siemens group.

For the CARES/Life reliability analysis we used the Weibull parameters obtained from the three-point flexure bars to predict the strength response of the disks. Utilizing equation (2) with maximum likelihood analysis and assuming volume flaws we obtained a Weibull modulus $\mathrm{m}_{\mathrm{V}}=11.96$, a characteristic strength $\sigma_{\theta \mathrm{V}}=612.7 \mathrm{MPa}$, and a Weibull scale parameter $\sigma_{0 \mathrm{~V}}=453.8 \mathrm{MPa} \cdot \mathrm{mm}^{3 / \mathrm{m}}$ for the flexure bars tested at room temperature. Using these values of $m_{V}$ and $\sigma_{0 \mathrm{~V}}$ and the results of the FEA with equation (4), the transient reliability response of the disk was calculated. For fast-fracture transient analysis, the time increment terms $\Delta \mathrm{t}$ can be set to zero and only $\sigma_{\text {Ieq,k,Tmax }}$ has to be determined. Since only one set of Weibull parameters at one temperature are used, $\sigma_{\text {Ieq,k,Tmax }}$ in this case is simply the maximum effective stress at $\Psi$ of all time steps used in the analysis. Material strength of ceramics (and hence Weibull and fatigue parameters) are known to be temperature dependent. Reference [10] shows this relationship for SN282, where average strength gradually lowers as temperature increases. We however, are not considering this dependency since only room temperature results were available for the bars cut from the disks. We believe this is still satisfactory since from Figure 1 (a) the temperatures near the edge of the disk (where fracture is most likely to occur) are relatively low such that deviation from room temperature values should be limited.

Figure 2 shows the predicted failure probability versus time for specimens \#3 and \#9. These results are obtained using volume based analysis with the Batdorf multiaxial methodology, a Griffith crack and $\overline{\mathrm{C}}=0.82$. The plot shows straight line segments connecting the failure probability predictions for the various time steps. Each time step is based on analysis results from the experimentally measured temperature profile. The solid line shows the results of the transient analysis from equation (4), while the dotted line are results from fast-fracture analysis of the individual time step. Notice that the dotted curve occasionally shows a lower failure probability than a previous time step, while the solid curve for the transient analysis correctly does not show this trend. Also, 


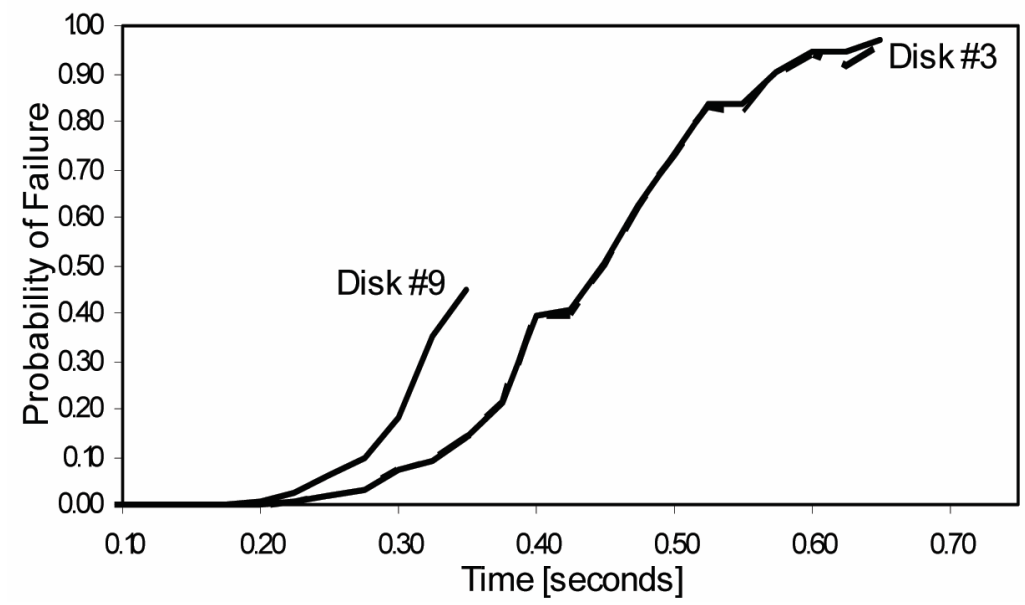

FIG. 2-Failure probability as a function of time for disk specimens \#3 and \#9. Solid line is transient fast-fracture prediction and dotted line is fast-fracture prediction for a particular time step.

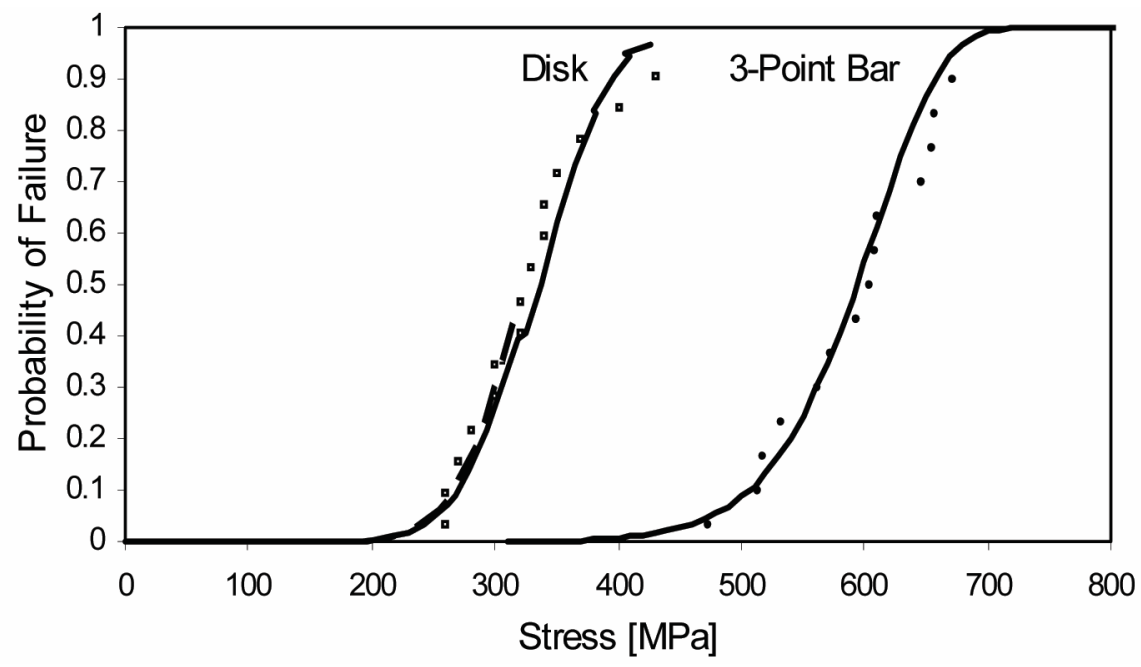

FIG. 3-Predicted failure probability of disk versus stress, $\sigma_{f}$, using the Weibull parameters estimated from the 3-point flexure bar data. Solid line is for specimen \#3 and dotted line is specimen \#9. Experimental rupture data also shown.

there is a close correlation between the transient fast-fracture results and the single-timestep fast-fracture results, increasing confidence of the validity of the new algorithm. The solid curve and the dotted curve of disk \#9 are virtually coincident. Disk \#3 and disk \#9 truncate at different failure probabilities because each failed at a different maximum stress $\sigma_{\mathrm{f}}$. Another interesting observation is that disk \#3 and disk \#9 appear to have somewhat different failure probability responses versus time. For potential follow-up work it would be interesting to compare the other disks to determine the range of responses.

Figure 3 shows the predicted failure probability response of the disk versus the maximum stress $\sigma_{\mathrm{f}}$ in the disk. The experimentally obtained fracture stresses are overlaid for comparison. The curve for the three-point flexure bar results represents a line of best 
fit to the data as previously described $\left(\mathrm{m}_{\mathrm{V}}=11.96\right.$, and $\left.\sigma_{\theta \mathrm{V}}=612.7 \mathrm{MPa}\right)$ that was used to obtain the Weibull parameters used for the disk reliability analysis $\left(\mathrm{m}_{\mathrm{V}}=11.96\right.$, and $\sigma_{0 \mathrm{~V}}=453.8 \mathrm{MPa} \cdot \mathrm{mm}^{3 / \mathrm{m}}$ ). The solid curve for the disk represents predictions based on the analysis of disk \#3, while the more difficult to see dotted curve is the prediction from disk \#9. Notice that the disk $\# 9$ results truncate around $\mathrm{P}_{\mathrm{f}}=0.45$ consistent with Figure 2. The curves for disk \#3 and \#9 follow nearly the same path in Figure 3, unlike the results shown in Figure 2. A striking observation about figure 3 is the difference in median strength between the disk and the three-point flexure bar. This primarily represents the "Weibull size-effect"-meaning that a component with a lot of volume under high stress will have a lower average strength than a component with a small amount of volume under high stress, and is a direct consequence of equation (2).

Another interesting item worth commenting on is the significant difference between the Weibull modulus $\mathrm{m}_{\mathrm{V}}$ for the three-point flexure bar rupture data $\left(\mathrm{m}_{\mathrm{V}}=11.96, \sigma_{\theta \mathrm{V}}=\right.$ $612.7 \mathrm{MPa})$ and that of the thermal shocked disk $\left(\mathrm{m}_{\mathrm{V}}=6.91, \sigma_{\theta \mathrm{V}}=345.9 \mathrm{MPa}\right)$ experimental rupture data (shown in Figure 3) as determined by CARES/Life maximum likelihood parameter estimation. Least squares regression (using an Excel spreadsheet) on the CARES/Life disk predictions curves shown in Figure 3 yields a Weibull modulus $\mathrm{m}_{\mathrm{V}}=8.72$. This is an interesting result because under usual circumstances the Weibull modulus for the test specimen and the designed component are presumed to be the same given that they are sampling similar flaw populations and that the effective volume $V_{e}$ stays constant. Meaning, under usual circumstances the Weibull modulus obtained from regression of the predicted disk failure probability curve versus strength would be 11.96, the same value as the three-point flexure specimen data. The fact that in this case the Weibull modulii between the predicted desk response curve and the flexure bar data are significantly different can be understood by examining Figure 1 (b). In the figure notice that as time increases, the amount of volume under high tensile stress significantly decreases. This has the effect of decreasing the effective volume $\mathrm{V}_{\mathrm{e}}$ with time, and through the size effect, increasing predicted failure stress $\sigma_{\mathrm{f}}$. The overall effect of this changing effective volume is to decrease the observed (apparent) Weibull modulus for the thermally shocked disks based on $\sigma_{f}$. The fact that CARES/Life predicts that the Weibull modulus obtained from the failure probability versus $\sigma_{\mathrm{f}}$ curve reduces to 8.7 compared to the flexure bar value of 12.0, compares favorably to the to the experimental disk result of 6.9. In other words, some of the discrepancy in the Weibull modulus values between the experimental disk and flexure bar results can be explained as a consequence of the transient thermal loads and how they influence the stress distribution in the disk as a function of time. The difference is not necessarily indicative of some error or inconsistency. The remainder of the difference can be explained as natural statistical variation (within $90 \%$ confidence bounds).

The excellent correlation in Figure 3 to experimental results must be considered within the context of the underlying statistics, given that the effective volumes $V_{e}$ between the three-point bend bar and the disk is large and sensitive to the value chosen for the Weibull modulus $m_{V}$. Because of the relative small number of samples tested (in this case 14 flexure specimens) and the large size effect, using Weibull parameters based on $90 \%$ confidence intervals from the three-point flexure bar data could shift the disk 
predictions significantly to the left and right of the experimental data. In general a good design practice would be to avoid large size-effect scalings between specimens and components unless experimental data exists for both specimen and component such that data pooling practices can be taken advantage of to obtain a set of best-fit Weibull parameters.

\section{Example 2: Diesel Exhaust Valve In Cyclic Loading}

This example, involving a heavy-duty diesel ceramic exhaust valve [21], was selected to contrast failure probability predictions for power law, Walker law and a proof test condition. The valves were made of NT-551 silicon nitride material. Table 1 contains a summary of the Weibull and SCG parameters obtained from four-point flexure bars at the three different temperatures [22]. CARES/Life was used to obtain these parameters using the raw data listed in reference [22]. Data to obtain values for the Walker law parameters did not exist, so assumed values for $Q_{V}$ and $A_{2} / A_{1}$ were used.

TABLE 1-NT551 fast fracture and SCG material properties.

\begin{tabular}{cccccccc}
\hline $\mathrm{T}\left({ }^{\circ} \mathrm{C}\right)$ & $\mathrm{m}_{\mathrm{V}}$ & $\begin{array}{c}\sigma_{0 \mathrm{~V}} \\
\left(\mathrm{MPa} \cdot \mathrm{mm}^{3 / \mathrm{m}}\right)\end{array}$ & $\begin{array}{c}\sigma_{\theta} \\
(\mathrm{Mpa})\end{array}$ & $\mathrm{N}_{\mathrm{V}}$ & $\begin{array}{c}\mathrm{B}_{\mathrm{V}} \\
\left(\mathrm{MPa}^{2} \cdot \mathrm{sec}\right)\end{array}$ & $\mathrm{Q}_{\mathrm{V}}$ & $\mathrm{A}_{2} / \mathrm{A}_{1}$ \\
\hline 20 & 9.4 & 1054 & 806 & 31.6 & $5.44 \mathrm{e} 5$ & 3.2 & 0.65 \\
700 & 9.6 & 773 & 593 & 86.5 & $1.12 \mathrm{e} 4$ & 3.2 & 0.65 \\
850 & 8.4 & 790 & 577 & 18.5 & $1.13 \mathrm{e} 6$ & 3.2 & 0.65 \\
\hline
\end{tabular}

Fifteen valves were engine tested without failure. These valves consisted of seven longitudinally machined valves and eight transversely machined valves. The transversely machined valves had been engine tested for 1000 hours while the longitudinally machined valves had been engine tested for 166 hours. These valves were subsequently tested in fast-fracture in order to examine their retained strength. The mode of failure for both valve-machining orientations was found to be volume induced.

Since all engine tested valves failed due to volume flaws, the valve's transient reliability was based on volume analysis. Figure 4 (a) shows the pressure variation as a function of time during a typical combustion cycle of 0.0315 seconds. The pressure is applied to the valve's face and other exposed surfaces within the cylinder. The maximum attained pressure during the combustion cycle was estimated to be $15.85 \mathrm{MPa}$ [21]. A $445 \mathrm{~N}(100 \mathrm{lb})$ force due to spring preload is applied to the valve stem when it is in the open position. At the moment the valve closes an impact force of $1335 \mathrm{~N}(300 \mathrm{lb})$ is applied to the valve stem. In addition, thermal stresses due to the temperature distribution in the valve are superposed to the mechanical stresses.

Figure 4 (b) shows the approximate mean thermal profile in the valve. Steady-state thermal analysis using ANSYS FEA code was conducted to compute these temperatures. This figure shows that the temperature is maximum near the valve face and decays towards the valve seat and stem.

Transient reliability analysis (using equations (7) and (9)) was conducted by dividing the load history into 29 time steps. During each step, the load was assumed constant. The loads corresponding to these time steps were modeled within the ANSYS FEA program, 


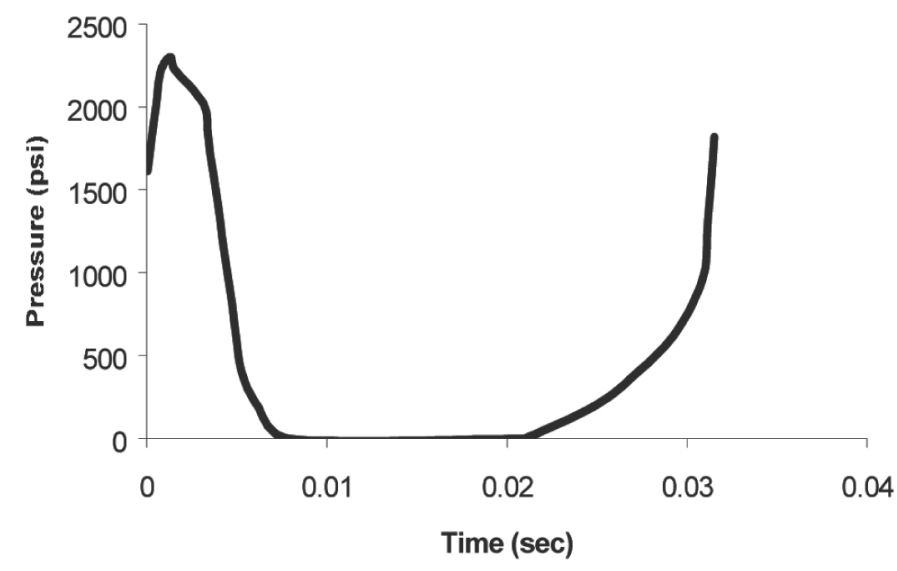

(b)

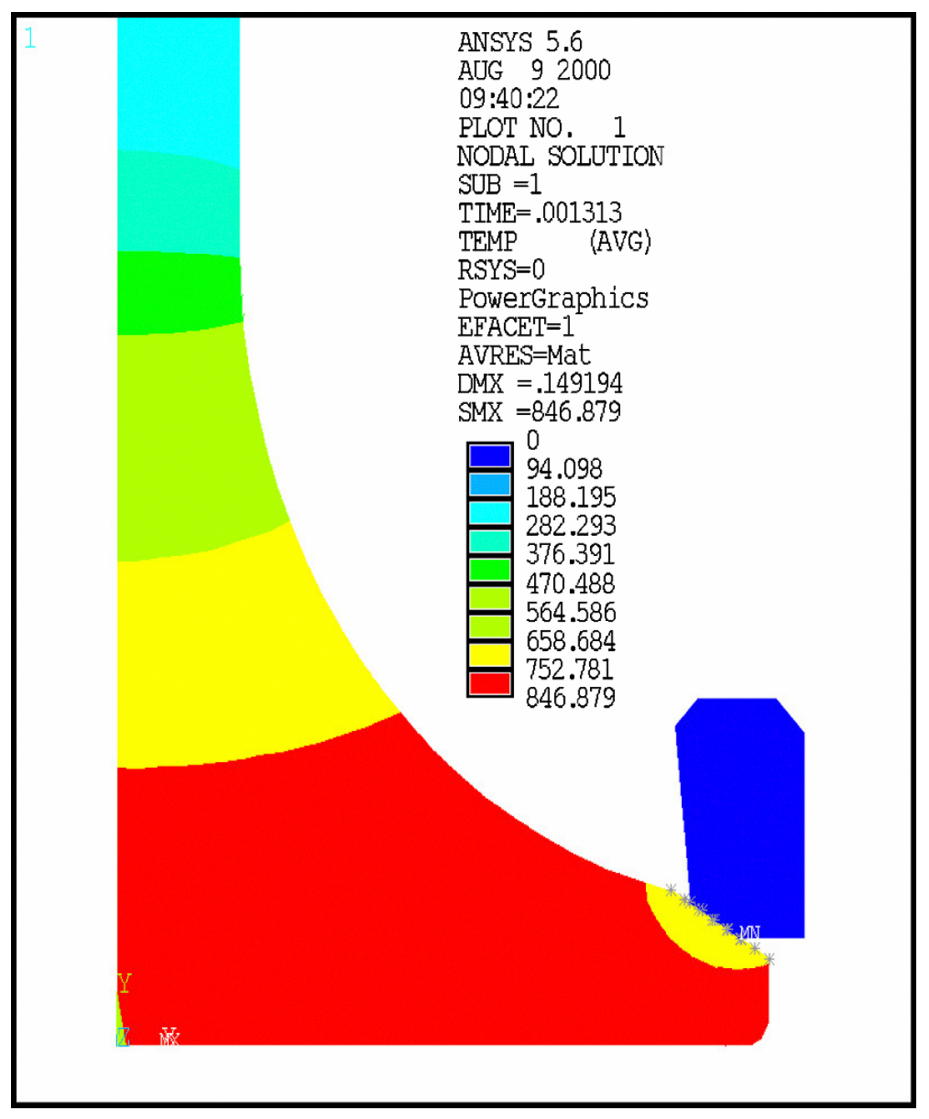

FIG. 4-Loading profile: (a) Pressure variation applied to the face of a ceramic valve during a typical engine combustion cycle, and (b) mean thermal profile.

which yielded the stress results for these 29 time steps (stress history). Figure 5 (a) highlights the first principal thermomechanical stress distribution in the valve at the moment of maximum applied pressure (at time step 6). From the figure it is apparent that the maximum stress location is at the valve radius, which is in agreement with the FEA results of Corum et al. [21]. 
(a)
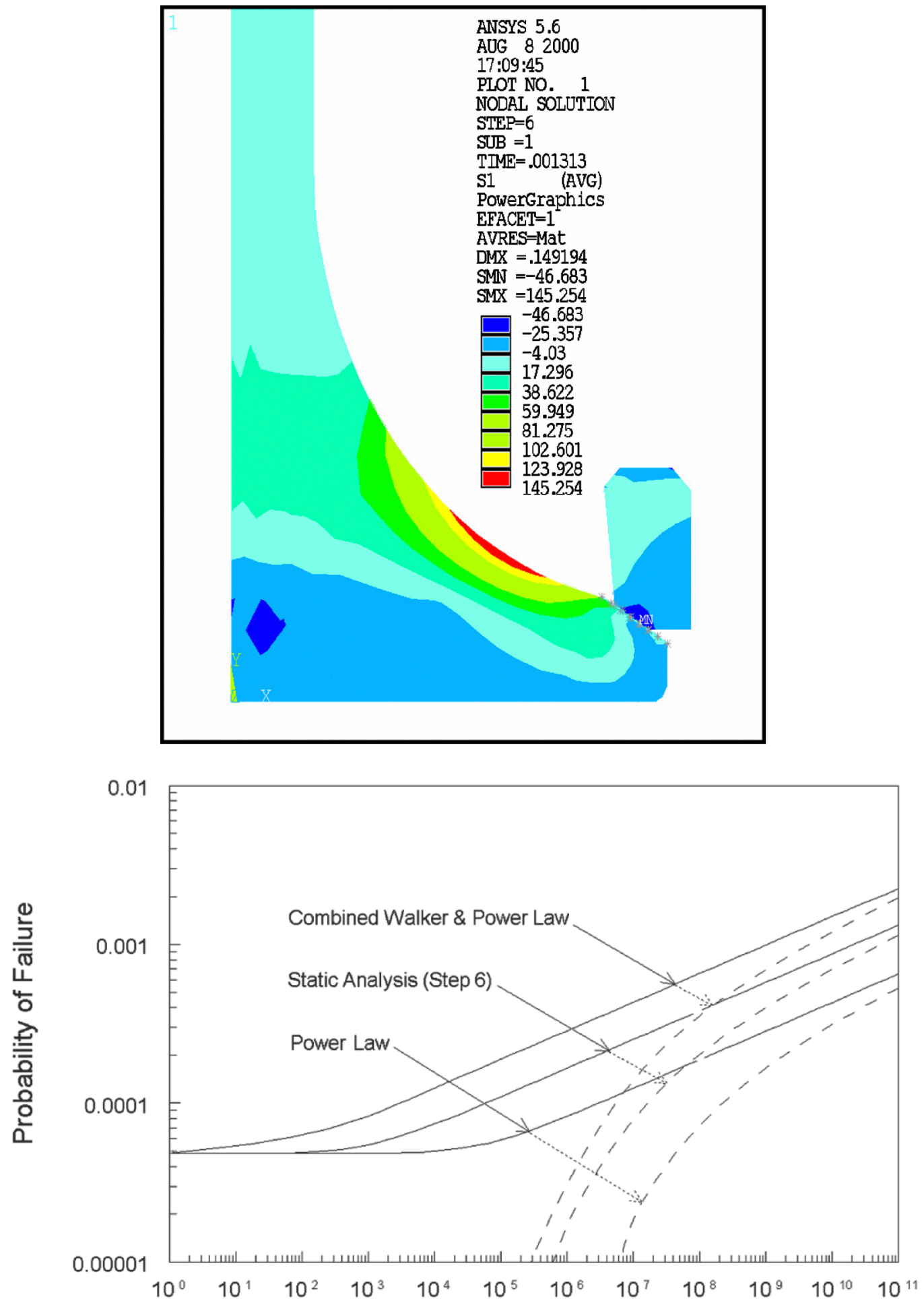

(b)

Cycles

FIG. 5-(a) First principal stress distribution in the valve at the moment of maximum applied pressure (MPa), (b) failure probability versus cycles for proof test (dotted lines) and non-proof-test (solid lines) conditions for a static load, power law, and combined law. 
The valve's stress history and other relevant terms (temperature, volume, material properties, element number, etc.) were subsequently read into CARES/Life. Figure 5 (b) shows the predicted failure probability as a function of cycles for various senarios. None of the tested valves failed, 8 of which were tested to 1000 hours (which corresponds to approximately $1.1 \times 10^{8}$ cycles). Thus the failure rate of the tested valves was less than 1 out of 8 at 1000 hours of operation. From Figure 5 (b) it can be seen that in fast-fracture (at one cycle with no SCG) about 5 out of 100,000 valves are predicted to fail from the loading. With SCG and the power law about 20 out of 100,000 valves fail after 1000 hours operation. If we conservatively assume that a worst-case load (time step 6) is applied over the whole engine cycle (static loading), then about 40 out of 100,000 valves fail after 1000 hours. Using the combined Walker-power law with the hypothetical parameters from Table 1 this rate increases to 70 out of 100,000 valves at 1000 hours. All of these rates were well below what was experimentally observed. These three scenarios were presented in order to contrast the predictions. The power law with cyclic loading predicts the least damage. The static loading scenario is predicted to be more damaging at double the rate of the cyclic loading. The combined Walker-power law predicts the most damage due to the enhanced cyclic fatigue effect. Since the effect of cyclic loads is unknown, a more conservative assumption is to assume static loading, however even this assumption can be un-conservative.

To reduce the predicted failure rate even further, proof testing can be applied to prevent the weakest components (those with the highest likelihood of failing) from being placed into service. Figure 5 (b) also shows the predicted results for the three various scenarios for an applied proof test of 10,000 cycles at a factor of 1.1 of the service loading (dotted lines in the figure). Increasing the proof test load reduces the attenuated probability of failure even further.

\section{Example 3: Alumina In Static Fatigue-Material Properties Changing with Time}

In this example we examine how the reliability response of a vitreous bonded alumina is hypothetically affected by Weibull and fatigue parameters that change over time. The two scenarios that are presented are strictly based on curve fitting the data. We do not have the sufficient information necessary to physically specify which parameters are really responsible for the change in material response with time. However, the point of this analysis is to present an analytical model which potentially can explain the nonlinear and changing rupture behavior of the material given that we know what physical parameters are responsible for the changing material behavior. This capability is potentially useful in modeling materials with changing composition (or changing physics of crack growth), including oxidation and crack blunting/healing phenomena.

The data for the example was obtained from Quinn [23] and consists of rupture lives of alumina four-point flexure bars in static fatigue (loading at a constant stress level over time). The specimens had average dimensions of $2.2 \mathrm{~mm}$ height, $2.8 \mathrm{~mm}$ width, a load span of $19.0 \mathrm{~mm}$, and a support span of $38.0 \mathrm{~mm}$. This data set was chosen from the literature because of its "non-ideal" behavior and the careful experimental technique reported by the author, which reduces the likelihood that equipment and measurement errors significantly affected the results. The rupture data for the individual specimens is shown in Figure 6. Testing was performed at $1000{ }^{\circ} \mathrm{C}$. The report stated that very little creep deformation was detected, and although fractography was attempted, it did not reveal the source of the strength limiting flaws. 
Two trends make this data non-ideally behaved: (1) dramatically increased scatter at lower applied stresses, and (2) pronounced nonlinear behavior in the stress rupture data as the applied stresses became lower (the strength data shifted to the right which signified that the lives became longer than would have been predicted if the standard power law was applicable). An ideally behaved data set would show a straight line trend indicating that the fatigue exponent is constant, also the scatter band would appear with a constant width versus the applied stress indicating the Weibull modulus is constant.

A confirmatory piece of evidence that material properties were changing with time was obtained by performing static rupture experiments on specimens that were annealed (at no load) for either 1 or 24 hours at a temperature of $1050{ }^{\circ} \mathrm{C}$. The outcome of these treatments (not shown herein) was that life dramatically increased versus exposure time for an applied stress level [23]. Quinn [23] indicated that the observed behavior is probably due to the partial devitrification of the material's glassy phase, resulting in an increased viscosity of the phase and a material with improved creep and stress rupture behavior. Quinn cites reference [24] to support this, although he concedes that crack blunting, healing, or residual stress changes could also be operative.

The data of Quinn defies the conventional modeling approach since the material properties could be changing over time. To account for this we show what happens when Weibull and fatigue parameters change with time for two cases; (1) changing the fatigue exponent $\mathrm{N}$ and the Weibull modulus over time, and (2) changing the Weibull parameters ( $\mathrm{m}$ and $\sigma_{0}$ ) over time. Tables 2 and 3 show the sets of parameters chosen to demonstrate these scenarios. Given the fact that no established parameter estimation techniques currently exist for this type of non-ideally behaved data, these parameters were iteratively selected to fit the data. Table 2 contains a set of parameters versus time where the fatigue exponent, $\mathrm{N}$,

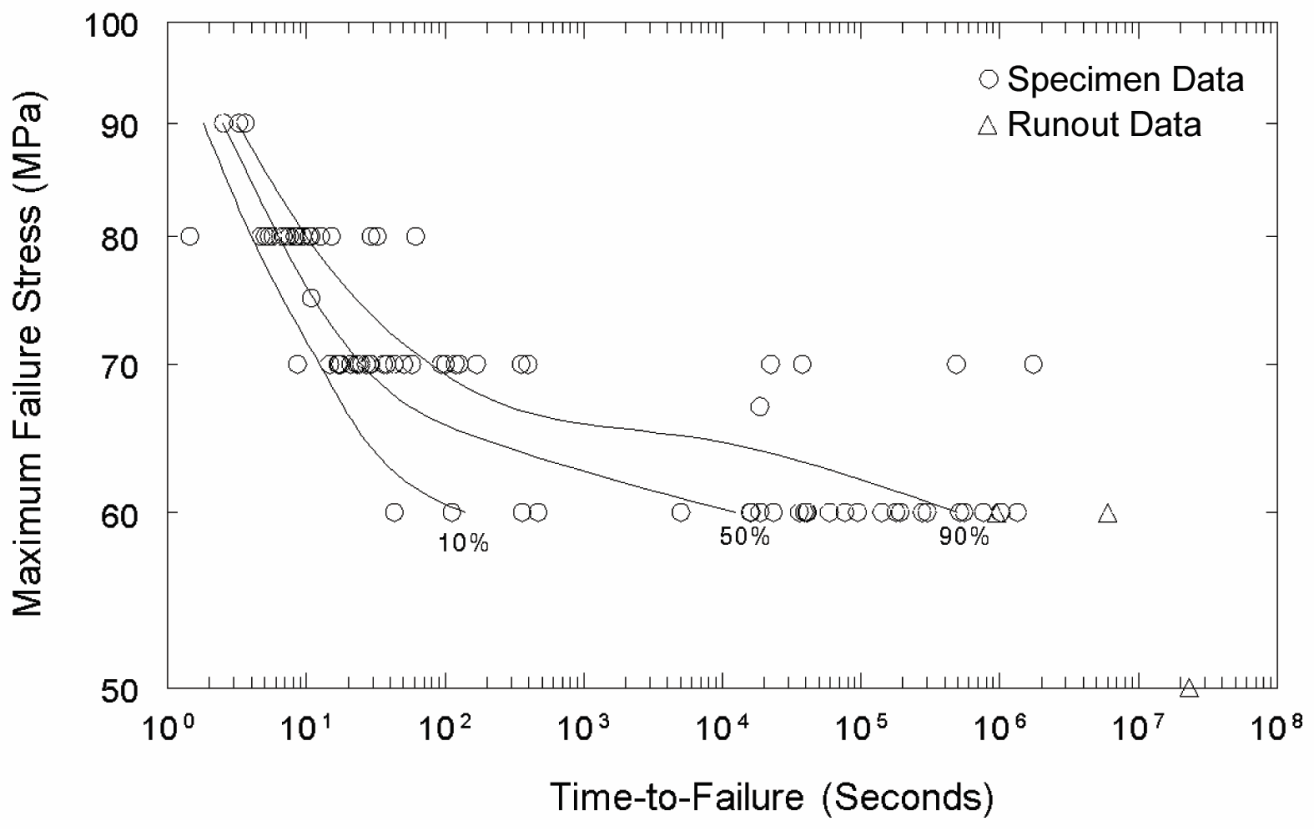

FIG. 6-Affect on failure probability of changing fatigue exponent, $N$, with the log of time from Table 2 on static fatigue rupture data of an alumina at $1000^{\circ} \mathrm{C}$. 
TABLE 2-Weibull and fatigue parameters associated with Figure 6.

\begin{tabular}{ccccc}
\hline $\mathrm{t}$ (seconds) & $\mathrm{m}_{\mathrm{S}}$ & $\begin{array}{c}\left(\sigma_{0 \mathrm{~S})}\right. \\
\left(\mathrm{MPa} \cdot \mathrm{mm}^{2 / \mathrm{m}}\right)\end{array}$ & $\mathrm{N}_{\mathrm{S}}$ & $\begin{array}{c}\mathrm{B}_{\mathrm{S}} \\
\left(\mathrm{MPa}^{2} \cdot \mathrm{sec}\right)\end{array}$ \\
\hline 1.6 & 29.4 & 156.8 & 6.7 & 2711.1 \\
31.6 & 15.8 & 152.7 & 13.2 & 9707.7 \\
$1.0 \mathrm{e} 5$ & 13.1 & 127.3 & 36.4 & 2276.2 \\
\hline
\end{tabular}

TABLE 3-Weibull and fatigue parameters associated with Figure 7.

\begin{tabular}{ccccc}
\hline $\mathrm{t}$ (seconds) & $\mathrm{m}_{\mathrm{S}}$ & $\begin{array}{c}\left(\sigma_{0 \mathrm{~S})}\right. \\
\left(\mathrm{MPa} \cdot \mathrm{mm}^{2 / \mathrm{m}}\right)\end{array}$ & $\mathrm{N}_{\mathrm{S}}$ & $\begin{array}{c}\mathrm{B}_{\mathrm{S}} \\
\left(\mathrm{MPa}^{2} \cdot \mathrm{sec}\right)\end{array}$ \\
\hline 1.6 & 29.4 & 165.8 & 6.7 & 2711.1 \\
31.6 & 7.4 & 263.3 & 8.0 & 2395.9 \\
316.2 & 4.5 & 870.1 & 9.0 & $10,389.0$ \\
\hline
\end{tabular}

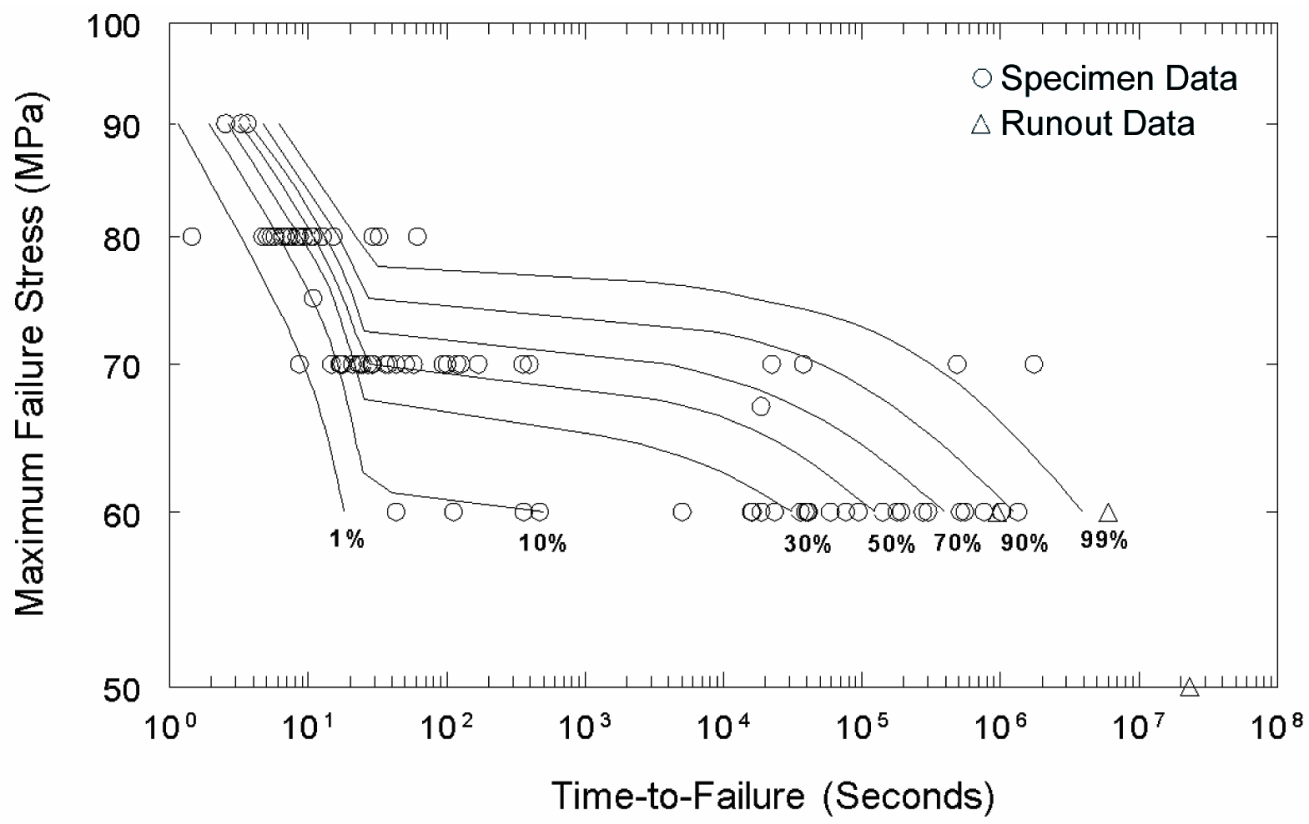

FIG. 7-Affect on failure probability of changing Weibull modulus, $m$, with the log of time from Table 3on static fatigue rupture data of an alumina at $1000^{\circ} \mathrm{C}$. 
and the Weibull modulus, $\mathrm{m}$, are varied to yield an improved fit to the data. Table 3 shows a set of parameters where the Weibull modulus, $\mathrm{m}$, is varied while the fatigue exponent, $\mathrm{N}$, is kept relatively constant. Note that in both cases the scale parameter $\sigma_{0}$ is dependent on the Weibull modulus, and B is dependent on the fatigue exponent as well as the Weibull parameters. When applying these parameter tables within a reliability analysis, the Weibull and fatigue parameters are linearly interpolated with the log of time within the time spans listed in the tables and are held constant outside of the time span.

Because of the simplicity of the four-point specimen loading and geometry, results from FEA were not needed for the reliability analysis. Instead, a closed form expression for the effective area, $A_{e}$, was used to evaluate the integral of equation (2) for a surface flaw failure mode [25]. An effective area of $58.0 \mathrm{~mm}^{2}$ was calculated based on a Weibull modulus value of 7.7. This value was chosen because sensitivity analysis using equation (2) indicated that the maximum error in strength for a given failure probability would be $1 \%$ or less for Weibull modulus values ranging between 5.0 and 30.0. This level of error is negligible for the illustrative purposes of this example. To model the transient material response 10 time steps are used per decade of the log of the time. Hence 10 time steps are used between 1 and 10 seconds, while 20 time steps are used between 1 and 100 seconds. The time steps are log increments of time - that is, they would appear as equally spaced increments in Figure 6 with 10 steps per decade.

Figure 6 shows the predicted 10\%, 50\%, and 90\% failure probability iso-lines for the parameters shown in Table 2, while Figure 7 shows 1\%, 10\%, 30\%, 50\%, 70\%, 90\%, and 99\% failure probability iso-lines for the parameters shown in Table 3. Neither plot represents an optimized set of fitted parameters. As previously stated no established parameter estimation techniques currently exist for this type of non-ideally behaved data. Parameters were obtained by segregating portions of the data and performing parameter estimation as described in [1] for the four-point bending bar specimen as well as further refinements by trial-and-error. Figure 6 shows that the curvature in the data can be captured by changing the fatigue exponent, $\mathrm{N}$, however, accounting for the change in scatter still required modifying the Weibull modulus, $\mathrm{m}$. Figure 7 is interesting because a satisfactory fit to the data can be obtained primarily by changing the Weibull modulus and scale parameter only ( $\mathrm{B}$ is changing mainly in response to these parameters). The "kink" shown in the failure probability iso-lines between 10 and 100 seconds is not purposely modeledthat is, we have not selected parameters values specifically to obtain this response. The "outlier" rupture data (data that appears to be not part of, or not consistent with, the main body of data) at long times to failure at $70 \mathrm{MPa}$ and the "outlier" data at short times to failure at $60 \mathrm{MPa}$ are better accounted for in the model compared to Figure 6. That is, data that visually appears as "outliers" are actually consistent with the flaw population failure probability response - in other words they are predicted to be there.

The modeling assumptions that produced the results in Figure 7 reasonably capture all of the trends in the data as well as or better than the approach used in Figure 6. Also, both approaches required changing the Weibull modulus to account for the range of scatter. A changing Weibull modulus could be indicative of new flaw generation, or it could be indicative of changes of the physics of crack growth associated with R-curve behavior. On the other hand a changing fatigue exponent with time is consistent with crack blunting/healing phenomena, where the crack velocity relationship in equation (5) is 
changing with time. In this case further tests on the material would be needed to understand the underlying mechanism that was driving the SCG behavior.

\section{Conclusions}

A methodology for computing the transient reliability in ceramic components subjected to fluctuating thermomechanical loading was developed and incorporated into the CARES/Life code. This enables CARES/Life to be used to predict component reliability for situations such as thermal shock, startup and shutdown conditions in heat engines, and cyclic loading. The methodology accounts for varying material response, whether due to temperature or environmental changes by allowing Weibull and fatigue parameters to vary over the loading history. Examples demonstrating the viability of the technique for fast-fracture, cyclic loading, and proof testing, were presented.

\section{References}

[1] Nemeth, N. N., Powers, L. M., Janosik, L. A., and Gyekenyesi, J. P., "TimeDependent Reliability Analysis of Monolithic Ceramic Components Using the CARES/LIFE Integrated Design Program," Life Prediction Methodologies and Data for Ceramic Materials, ASTM STP 1201, C. R. Brinkman, and S. F. Duffy, Eds., American Society for Testing and Materials, Philadelphia, 1993, pp. 390-408.

[2] Peralta, A. D., Wu, D. C., Brehm, P. J., Cuccio, J. C., and Menon, M. N., "Strength Prediction of Ceramic Components Under Complex Stress States," Allied Signal Document No. 31-12637, 1995.

[3] Heger, A., "Stau Programm Berech," Ph.D. Thesis, Karlsruhe University, Karlsruhe, Germany, 1991.

[4] Paluszny, A. and Nicholls, P. F., "Predicting Time-Dependent Reliability of Ceramic Rotors," Ceramics for High Performance Applications-II, J. Burke, E. Lenoe, and N. Katz, Eds., Brook Hill, Chesnut Hill, Massachuestts, 1978.

[5] Stanley, P. and Chau, F. S., "A Probabilistic Treatment of Brittle Fracture Under Non-monotonically Increasing Stresses," International Journal of Fracture, Vol. 22, 1983, pp. 187-202.

[6] Ziegler, C., "Bewertung der Zuverlassigkeit Keramischer Komponenten bei zeitlich veranderlichen Spannungen und bei Hochtemperaturbelastung," Ph.D. Thesis, Karlsruhe University, Karlsruhe, Germany, 1998.

[7] Jadaan, O. M. and Nemeth, N. N., "Transient Reliability of Ceramic Structures," Fatigue \& Fractue of Engineering Materials and Structures, Vol. 24, 2001, pp. 475-487.

[8] Nemeth, N. N. and Jadaan, O. M., "Transient Reliability of Ceramic Structures For Heat Engine Applications," Proceedings of the 5th Annual FAA/Air Force/NASA/Navy Workshop on the Application of Probabilistic Methods to Gas Turbine Engines, June 11-14, 2001, Westlake, Ohio.

[9] Weibull, W. A., "A Statistical Theory of the Strength of Materials," Ingenoirs Vetenskaps Akadanien Handlinger, No. 151, 1939. 
[10] Batdorf, S. B. and Crose, J. G., "A Statistical Theory for the Fracture of Brittle Structures Subjected to Nonuniform Polyaxial Stresses," Journal of Applied Mechanics, Vol. 41, No. 2, June 1974, pp. 459-464.

[11] Batdorf, S. B. and Heinisch, H. L., Jr., "Weakest Link Theory Reformulated for Arbitrary Fracture Criterion," Journal of the American Ceramic Society, Vol. 61, No. 7-8, 1978, pp. 355-358.

[12] Wiederhorn, S. M., "Subcritical Crack Growth in Ceramics," Fracture Mechanics of Ceramics, R. C. Bradt, D. P. H. Hasselman, and F. F. Lange, Eds., Vol. 2, Plenum Press, New York, NY, 1974, pp. 613-646.

[13] Shetty, D.K., "Mixed-Mode Fracture Criteria for Reliability Analysis and Design with Structural Ceramics," Journal of Engineering Gas Turbines \& Power, Vol. 109, No. 3, July 1987, pp. 282-289.

[14] Walker, K., "Effects of Environmental and Complex Load History on Fatigue Life," ASTM STP 462, American Society for Testing and Materials, Philadelphia, PA., 1970, p. 1.

[15] Rahman, S., Nemeth, N.N., and Gyekenyesi, J.P., "Life Prediction and Reliability Analysis of Ceramic Structures Under Combined Static and Cyclic Fatigue," 1998 ASME Turbo Expo-Land, Sea, and Air, Stockholm Sweden, June 2-5, 1998, Paper No. $98-$ GT-569.

[16] Ferber, M., Kirchhoff, G., Hollstein, T., Westerheide, R., Bast, U., Rettig, U., and Mineo, M., "Thermal Shock Testing of Advanced Ceramics-Subtask 9." International Energy Agency Implementing Agreement For a Programme of Research and Development on High Temperature Materials for Automotive Engines, prepared for The Heavy Vehicle Propulsion System Materials Program Oak Ridge National Laboratory for the U.S. Department of Energy, M00-107208, March 2000.

[17] Rettig, U., Personal communication, August, 2002.

[18] Kirchoff, G., Holzherr, M., Bast, U., and Rettig, U., "Thermal Shock and Thermal Cycling Behavior of Silicon Nitride Ceramics," Proceedings of the International Conference on Silicon Nitride-Based Ceramics, October 4-6, 1994, Stuttgart, Germany. Published by Trans Tech Publications Ltd, Switzerland, in Key Engineering Materials, Vol. 89-91, 1994, pp. 605-610.

[19] Rettig, U., Laserschock-Meßmethode-“Ein Quantitatives Verfahren Zur Charakterisierung Der Temperature-Wechselbestandigkeit Hochfester Keramischer Werkstoffe," Eingereicht an der Fakultat Maschinenwesen der Technischen Universitat Dresden zur Erlangung der Wurde Eines Doktors der Ingenieurwissenschaften (Dr.-Ing.), October 16, 1997.

[20] Ferber, M., Personal communication, July, 2002.

[21] Corum, J., Battiste, R., Gwaltney, R., and Luttrell, C., "Design Analysis and Testing of Ceramic Exhaust Valve for Heavy Duty Diesel Engine," Oak Ridge National Laboratory, ORNL/TM-13253, 1996.

[22] Andrews, M. A., Wereszczak, A. A., Kirkland, T. P., and Breder, K., "Strength and Fatigue of NT551 Silicon Nitride and NT551 Diesel Exhaust Valves," Oak Ridge National Laboratory, ORNL/TM-1999/332, 1999. 
[23] Quinn, G. D., "Delayed Failure of a Commercial Vitreous Bonded Alumina," Journal of Materials Science, Vol. 22, 1987, pp. 2309-2318.

[24] Wiederhorn, S., Hockey, B., Krause, K. Jr., and Jakus, K., "Creep and Fracture of a Vitreous-Bonded Aluminum Oxide," Journal of Materials Science, Vol. 21, 1986, pp. 810 .

[25] Nemeth, N. N., Powers, L. M., Janosik, L. A., and Gyekenyesi, J. P., "Ceramics Analysis and Reliability Evaluation of Structures Life Prediction Program Users and Programmers Manual," NASA/TM-2003-106316, NASA Glenn Research Center, 2003. 


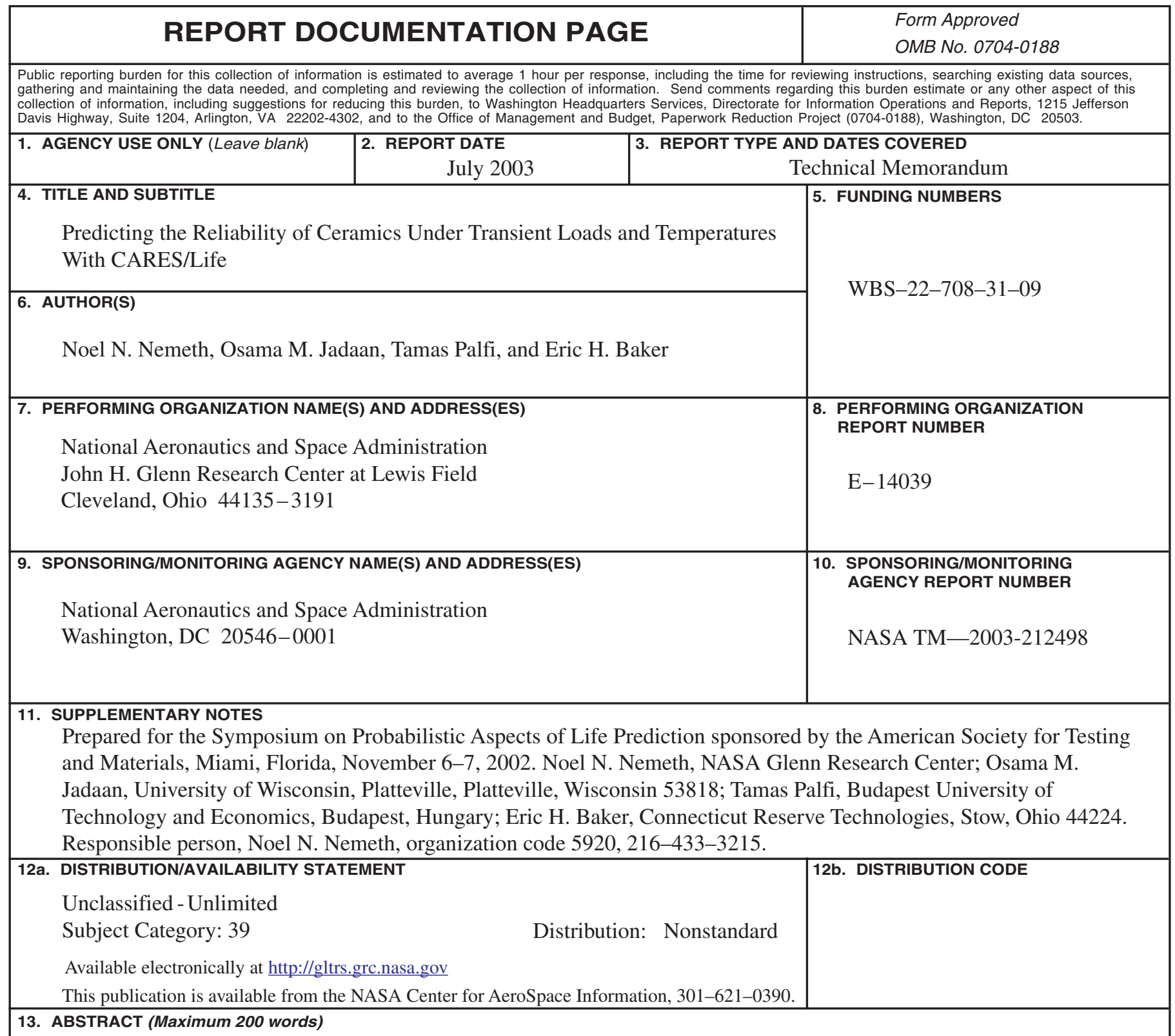

A methodology is shown for predicting the time-dependent reliability of ceramic components against catastrophic rupture when subjected to transient thermomechanical loads (including cyclic loads). The methodology takes into account the changes in material response that can occur with temperature or time (i.e., changing fatigue and Weibull parameters with temperature or time). This capability has been added to the NASA CARES/Life (Ceramic Analysis and Reliability Evaluation of Structures/Life) code. The code has been modified to have the ability to interface with commercially available finite element analysis (FEA) codes executed for transient load histories. Examples are provided to demonstrate the features of the methodology as implemented in the CARES/Life program.

\begin{tabular}{|c|c|c|c|}
\hline \multicolumn{3}{|l|}{ 14. SUBJECT TERMS } & 15. NUMBER OF PAGES \\
\hline \multirow{2}{*}{\multicolumn{3}{|c|}{$\begin{array}{l}\text { Reliability; Transient; Weibull; Cyclic; Fatigue; Failure; CARES/Life; Ceramics; Strength; } \\
\text { Life prediction }\end{array}$}} & 28 \\
\hline & & & 16. PRICE CODE \\
\hline $\begin{array}{l}\text { 17. SECURITY CLASSIFICATION } \\
\text { OF REPORT }\end{array}$ & $\begin{array}{l}\text { 18. SECURITY CLASSIFICATION } \\
\text { OF THIS PAGE }\end{array}$ & $\begin{array}{l}\text { 19. SECURITY CLASSIFICATION } \\
\text { OF ABSTRACT }\end{array}$ & 20. LIMITATION OF ABSTRACT \\
\hline Unclassified & Unclassified & Unclassified & \\
\hline
\end{tabular}

